reader. The answers are given at the back, and they should be tackled by every serious student. The book is very well produced, and the numerous diagrams are beautifully clear. Here and there a "bij" and a "probleem" have escaped the proof reader to remind us that this book is published in the Netherlands. Prof. Zernike's meaning is always clear although his English is occasionally unorthodox. These are not criticisms of the work; they add to the delight of reading it.

This book should be owned by every library and every serious student of the phase rule. It can be put alongside Roozeboom; no further praise is nocessary.

\section{PROPERTIES OF SYNTHETIC PIEZOELECTRIC CRYSTALS}

\section{Piezoelectricity}

(General Post Office : Selected Engineering Reports.) Pp. $x+369$. (London : H.M. Stationery Office, 1957.) $75 s$. net.

A $S$ stated in the foreword, this volume is the first of its kind which makes available to the general public the results of engineering reports of the English General Post Office. This report by the staff of the Materials Division of the Research Branch is in the field of synthetic piezoelectric crystals. Dr. R. Bechmann (now at the U.S. Army Signal Corps Engineering Laboratory, Fort Monmouth, New Jersey) was responsible for the theoretical investigations and indicated suitable fields for experimentation. A. C. Lynch, and later P. L. Parsons, were responsible for the physical measurements. Dr. R. Taylor supervised the erystal-growing experiments. The preparation of the reports for publication was undertaken by Dr. R. Taylor and Mrs. S. Ayers.

The book starts out with a general description of the fundamental properties of piezoelectric crystals. The notation for the fundamental quantities, and for rotated cuts, follows that standardized by the Piezoelectric Committer of the Institute of Radio Engineers (United States). A chapter on the use of tensor transformation in calculating the properties of rotated cuts was written by Bechmann. Since all the properties of the crystal are measured by means of the resonant and unti-resonant frequencies of fundamental modes, a complete discussion of modes of motion is given by Bechmann and Ayers. A feature of this discussion is the use of contour modes for measurements. However, little mention is made of the very extensive thickness mode solutions obtained recently by Prof. R. D. Mindlin and his associates at Columbia University.

These studies are preliminary to the determination of crystal constants by resonant frequency and capacitance measurements. A chapter by Lynch and Parsons discusses automatic methods for tracing out such resonances. The coupling factor is determined by the difference in capacitance above and below the resonant frequency.

Next follow chapters on methods for growing water-soluble crystals, for measuring their orientations by X-rays and for cutting them with wet string saws. The crystals studied seem to be nearly identical with those studied at Bell Laboratories as substitutes for quartz in filter plates and for under. water-sound transducers. The particular crystals studied are ammonium dihydrogen phosphate, sodium chlorate and sodium bromate, ethylenediamine tartrate, lithium sulphate monohydrate and di-potassium tartrate. A rather complete study has been made of the tartrates, but no new crystals are produced. Very complete determinations have been made for the elastic, piezoelectric and dielectric constants of these crystals, which will probably remain the most authoritative determinations of these properties.

The present reviewer misses a chapter giving a survey of probable uses for such crystals. In the United States, the only water-soluble crystal which survived competition with natural and synthetic quartz is ammonium dihydrogen phosphate, which is still used in underwater sound equipment. This may not be true in Britain. In any event, the series of reports can be recommended as giving a very broad background in piezoelectric crystal investigations and as containing the most recent set of elastic, piezoelectric and dielectric constants for piezoelectric crystals. The general idea of making available for wider circulation a series of engineering reports of one organization is also a commendable one and should be extended further.

WARREN P. MASON

\section{HAEOLYTIC DISEASE OF THE NEW-BORN}

\section{Comparative Aspects of Hæmolytic Disease of the} Newborn

By G. Fulton Roberts. Pp. 199. (London : William Heinemann (Medical Books), Ltd., 1957.) 17s. 6d. net.

7 HIS account of hæmolytic disease of the new-

born in man and animals is divided into nine chapters. The first, which deals with the history of the human disease, will probably be of limited appeal, but it serves a very useful purpose in giving proper credit to earlier workers in what is often assumed to be a modern preserve. Chapters 2 and 3 deal with hæmolytic anæmia and the problem of kernicterus, respectively. The latter chapter clearly suffers from the lack of knowledge on neonatal jaundice and the metabolism of the bile pigments, but the author comes through this ordeal well and is on firmer ground when discussing serological considerations in Chapter 4, which is stimulating and very much to the point.

At this stage, Dr. Roberts leaves the human infant and discusses, in two chapters, the disease as it is seen in the horse and the pig, and then, in Chapter 7, work on the experimental production of the condition. His grasp of the veterinary aspects of hæmolytic disease is sure and there is no lack of balance between human and veterinary medicine throughout the book. Chapter 8 is devoted to comparative pathology, and here the author best exhibits his gift for bringing together and assessing widely scattered data. A final chapter on treatment is brief but adequate for a book of this type.

In an age of increasing specialization, it is a pleasure to find an author who can see a disease as a whole. But Dr. Roberts does more than this in venturing along the many scientific paths that radiate from the clinical case. The book is written clearly and with great economy of words, and although the author describes it as a short account of present-day views it is, in fact, a comprehensive review with more than five hundred references. 